\section{Die Geschichte von TARMED und dem Mahlstein}

\author{
U. Steiner-König, Vizepräsidentin der FMH
}

Anlässlich der Jubiläumsfeier der FMH erschien es uns Mitgliedern des Zentralvorstands auch angezeigt, unserem Präsidenten für seine Beharrlichkeit im Rahmen der langjährigen GRAT-/TARMED-Verhandlungen zu danken. Schliesslich hatte die Ärztekammer gerade zwei Tage vor diesem Jubiläum JA gesagt $\mathrm{zu}$ Tarifstruktur und Rahmenverträgen, wobei da unmissverständlich Unvollendetes zur Kenntnis genommen werden musste. Das Geschenk an ihn? Ein Mahlstein! - «Ein Mahlstein, dessen Heimat die Wüste gewesen" (ich hatte ihn auf einer Wanderung in der Sahara durch glücklichen Zufall gefunden) «und der durch vielen Gebrauch unglaublich handlich geworden war. Wir wünschen dem Präsidenten, dass es ihm und uns mit TARMED, wenn er dereinst zur Routine geworden sein wird, ebenso ergehen möge».

Tatsächlich: In grosse und kleine, rechte und linke Hände passt dieser Stein. Seine Oberfläche ist durch den vielen Gebrauch geglättet. Seine klaren Konturen und Rundungen lassen die Hand, die ihn ergreift, sogleich erkennen, wie sie ihn handhaben muss. Setzen wir den Vergleich fort: TARMED ist den Verhandlungspartnern vertraut geworden. In Tat und Wahr-

Korrespondenz:

Dr. med. Ursula Steiner-König

Kirchenfeldstrasse 1

CH-3250 Lyss heit trifft dies für eine Handvoll Personen zu - die Winkelriede der Institutionen, die sie vertreten. Das Fussvolk der FMH (aber auch der Versicherer!) sieht den Stein von weitem und fragt sich, ob er einer heissen Kartoffel gleichzusetzen sei, ob er für eine Schleuder vorgesehen sei oder gar als Bumerang auf sie zurückzufliegen drohe. Und die Politiker und Politikerinnen möchten ihn nur allzu gerne zum Spielzeug haben.

Liebe Kolleginnen und Kollegen: Da ist der Stein - ein "Stein der Weisen» nur bedingt. Es ist noch niemandem je gelungen, aus alltäglichem Gebrauchsmaterial Gold herzustellen. Aber wir können durch alltäglichen Gebrauch solches Material je länger, desto besser kennenlernen. Jeder und jede hat seine/ ihre Werkzeugkiste zur Hand und kann durch persönlichen Einsatz zum Perfektionieren des Produkts beitragen. Sollte allerdings das Unglück passieren, dass uns der Stein als Spielzeug entrissen wird, könnten wir nur noch davon träumen, ihn für unseren täglichen Gebrauch noch perfekter, handlicher zu gestalten. Es müsste von einem bösen Fluch gesprochen werden, der über uns käme: Unsere berufliche Freiheit, unsere Stärke, die nur durch mutige Einigkeit bewahrt werden kann, wäre am Beginn des 2. Jahrhunderts des Bestehens unserer Verbindung dahin. Wer sollte sie dann - und wie? - zurückerobern? Von "zurückgewinnen" wage ich nicht zu reden. Was wir kennen, können wir - mit vereinten Anstrengungen - auch zähmen, können der jüngeren Generation von Kolleginnen und Kollegen unsere Erfahrungen darin weitergeben, damit sich auch ihre Werkzeugkiste mit Verhandlungsgeist und Sinn für Taktik ausstatten lässt.

Aber: Würde TARMED zum Spielzeug der Politikerinnen und Politiker, würde er womöglich für uns zum Trojanischen Pferd. Sie erinnern sich doch hoffentlich: Kassandra hatte vor dem Untergang Trojas gewarnt - und ihr wurde kein Glaube geschenkt. Lassen Sie mich nicht zur Kassandra verkommen! Besser einen unvollkommenen Stein der Weisen in der Hand als ... 